\title{
Disruption of the Trichoderma reesei cbh2 gene coding for cellobiohydrolase II leads to a delay in the triggering of cellulase formation by cellulose
}

\author{
Bernhard Seiboth, Robert Messner, Franz Gruber and Christian P. Kubicek* \\ Abteilung für Mikrobielle Biochemie, Institut für Biochemische Technologie und Mikrobiologie der TU Wien, \\ Getreidemarkt 9, A-1060 Wien, Austria
}

(Received 14 October 1991; revised 3 January 1992; accepted 3 March 1992)

\begin{abstract}
The role of the major conidial-bound cellulase - cellobiohydrolase II (CBH II) - in the triggering of cellulase formation in the fungus Trichoderma reesei was investigated by comparing the mutant strain QM 9414 with a recombinant strain unable to produce CBH II. For this purpose, the $c b h 2$ gene was isolated from a chromosomal gene bank of $T$. reesei, cloned into pGEM-7Zf( + ), and disrupted by insertion of the homologous pyr4 gene in its coding region to yield the plasmid vector pSB3. Transformation of the auxotrophic, pyr4-negative strain $T$. reesei TU-6 with pSB3 yielded 23 stable prototrophs, of which three were unable to produce CBH II - assessed by means of a monoclonal antibody - during growth on lactose or in the presence of sophorose. However, they formed cellobiohydrolase I (CBH I) at a rate comparable to strain QM 9414 under these conditions. Southern analysis of DNA of some $\mathrm{CBH} \mathrm{II}^{-}$and $\mathrm{CBH} \mathrm{II}^{+}$transformants confirmed that $\mathrm{pSB3}$ had integrated at the $c b h 2$ locus in the CBH II $^{-}$strains. The latter displayed normal growth on glucose or maltose as carbon source. They showed retarded growth on cellulose as sole carbon source, however, and exhibited a lag in the time course of CBH I and EG I formation, although producing roughly the same final cellulase activities. It is concluded from these results that CBH II is not essential for induction of cellulase formation by cellulose, but that it contributes significantly to the formation of lower molecular mass inducers in the early phase of growth of the fungus on cellulose.
\end{abstract}

\section{Introduction}

Cellulolytic enzymes are adaptively formed by fungi, but the respective mechanisms mediating this adaption are still only rudimentarily known. In the fungus Trichoderma reesei, the mechanism by which cellulose triggers cellulase formation has been demonstrated to involve constitutive, conidial-bound cellulases (Kubicek et al., 1988; El-Gogary et al., 1989). This apparently enables the fungus to form a limited amount of cellulose degradation products upon initial contact with cellulosic substrates, which may either themselves be or become converted to the inducer of cellulase formation. This idea is supported by the demonstration both of a constitutive $\beta$-glucosidase and a constitutive $\beta$-linked disaccharide permease in $T$. reesei (Umile \& Kubicek, 1986; Kubicek, 1987; Fritscher et al., 1990).

\footnotetext{
* Author for correspondence. Tel. 222588 014708; fax 2225874835. Abbreviations: CBH I, II, cellobiohydrolase I, II; EG I, endoglucanase I.
}

The enzyme spectrum of the cellulase complex in $T$. reesei conidia is different from the one secreted into the medium. Thus, the predominant conidial cellulase is not cellobiohydrolase (CBH) I - which accounts for more than $60 \%$ of total secreted protein (Enari \& NikuPaavola 1987; Kubicek, 1992) - but rather cellobiohydrolase II, which is only about $15 \%$ of total secreted protein (Messner et al., 1991). A major involvement of CBH II in the triggering of cellulase formation by cellulose has been confirmed by amplification of the $c b h 2$ gene in $T$. reesei, which resulted in recombinant strains in which cellulase formation was more efficiently induced by cellulose (Kubicek-Pranz et al., 1991; Messner et al., 1991). This suggests a major role of CBH II in cellulase induction.

In order to further support this possibility, we have constructed recombinant strains of $T$. reesei that contain a disrupted copy of the $c b h 2$ gene, and have analysed inducibility of cellulase formation by cellulose in these strains. 


\section{Methods}

Organisms. Trichoderma reesei $\mathrm{QM} 9414$ was used for the construction of the genomic library. $T$. reesei TU-6, a pyr4 auxotrophic mutant strain (Gruber et al., 1990a) derived from $T$. reesei QM 9414, served as transformation host. As stated previously (Gruber et al., 1990b), the term pyr4 rather than pyrG is preferred, since the gene contains no introns.

Media and conditions for cultivation. Conditions for growth of $T$. reesei strains in submerged culture on cellulose or other carbon sources have been described previously (Kubicek, 1982). For induction by sophorose in a replacement system, mycelia were pre-grown for $20 \mathrm{~h}$ with glycerol as a carbon source, and then transferred to medium free of carbon source as described by Sternberg \& Mandels (1979), and cultivated therein for a further $24 \mathrm{~h}$. Conidia for inoculations were obtained by growing $T$. reesei strains on malt agar plates for $14 \mathrm{~d}$ at $28^{\circ} \mathrm{C}$.

Cloning of cbh2 and gene disruption. Chromosomal DNA from $T$. reesei, grown in minimal medium, was isolated as described previously (Gruber $e t a l ., 1990 a$ ). The DNA was partially digested with $M b o I$ and the resulting fragments of 15-22 kb were ligated into lambda EMBL3, previously cut with BamHI. DNA was packaged into lambda particles in vitro and transfected into $E$. coli NM 539. Plaques of the Trichoderma gene bank were transferred onto nitrocellulose membrane filters (BA85, Schleicher and Schuell) and hybridized with a ${ }^{32} \mathrm{P}$-labelled nick-translated DrallI fragment of the $T$. reesei $c b h 2$ gene from $T$. reese $i$ L27, kindly supplied by Dr M. Ward (Genencor Int., South San Francisco, CA, USA). Hybridization was carried out at $66^{\circ} \mathrm{C}$ for $18 \mathrm{~h}$. The filters were then washed twice with $5 \times \mathrm{SSC}$, additionally containing $0.1 \%(w / v)$ SDS and $0.1 \%(w / v)$ sodium pyrophosphate $\left(30 \mathrm{~min}, 66^{\circ} \mathrm{C}\right.$ ), followed by two further washings with $0.3 \times \mathrm{SSC}$ (containing the same additives as above; $30 \mathrm{~min}, 60^{\circ} \mathrm{C}$ ). The filters were exposed on Kodak X-OMAT AR film at $-70^{\circ} \mathrm{C}$ using intensifying screens. From 19000 plaques screened, 40 gave a positive hybridization signal; these were purified and their DNA was subsequently isolated. A $4.2 \mathrm{~kb} E c o$ RI fragment containing the $c b h 2$ gene and its flanking regions was isolated from one of them, and cloned into the EcoRI site of the polylinker in the lacZ gene in pGEM-7Zf(+) to yield $\mathrm{pSB} 1$.

The plasmid pSB3 (see Fig. 1) was used to replace a portion of the host $c b h 2$ gene with the homologous pyr4 gene. To construct this vector a $2.7 \mathrm{~kb}$ Sal I fragment of pFG1 (Gruber et al., 1990b), containing the pyr4 gene and flanking regions, was cloned into the unique Sall site of pSBl containing $c b h 2$.

To disrupt the $T$. reesei TU-6 $c b h 2$ gene, it was transformed with pSB3 essentially as described previously (Gruber et al., 1990a).

Enzyme assays. Cellulase activity was assayed by measuring 'carboxymethylcellulase' (CMC-ase) activity as described previously (Kubicek et al., 1988).

Quantification of $C B H$ I and II. CBH I and II were quantified by a dot-blot immunotechnique using the monoclonal antibodies $\mathrm{CH}-5$ and CE-16 (Mischak et al., 1989).

Electrophoretic separation of cellulases and immunodetection. Culture supernatants were mixed with $0.5 \mathrm{vol}$. of $3 \times$ electrophoresis sample buffer (Laemmli, 1970), boiled for $5 \mathrm{~min}$, and centrifuged in an Eppendorf centrifuge ( $5 \mathrm{~min}$, full speed). A sample $(15 \mu \mathrm{l})$ of this supernatant was then loaded on $7.5 \%(w / v$, polyacrylamide) gels (Laemmli, 1970) and subjected to SDS-PAGE. The separated proteins were then blotted to nitrocellulose (Burnette, 1981), followed by staining with monoclonal antibodies as described by Mischak et al. (1989). The monoclonal antibodies for detection of CBH I, CBH II and EG I were CH-5, CE-16 and EG-3, respectively (Mischak et al., 1989; Luderer et al., 1991). Freshly prepared substrate solutions were used for each staining experiment. If the intensity of staining was to be compared, samples were loaded on the same gel. If two different antibodies were used to stain proteins on one single blot ('doubleimmunostaining'), this was done in a sequential order, starting with CH-5.

\section{Results}

\section{Construction of $T$. reesei recombinant strains lacking CBH II formation}

To generate strains of $T$. reesei that were specifically deficient in the production of CBH II, we employed a gene replacement strategy similar to that described by Miller et al. (1985). First (Fig. 1), we constructed a gene replacement vector, called pSB3; this contains a selectable pyr4 gene from $T$. reesei, which is inserted into the coding region of the $c b h 2$ genomic clone. This vector was used to transform a pyr 4 auxotroph of $T$. reesei (strain TU-6).

A total of $23 \mathrm{pyr}^{+}$transformants were screened for CBH II expression (by SDS-PAGE/Western blotting/ 'double immunostaining') during growth on lactose as a carbon source. The rationale behind this was that lactose promotes cellulase formation by $T$. reesei (Mandels, 1982), while growth on lactose is independent of the amount of cellulases secreted and hence not influenced by the possible lack of CBH II in some transformants. This eliminated the possibility of not finding putative CBH II- strains, due to their expected poor growth on cellulose. Three $\mathrm{CBH} \mathrm{II}^{-}$candidates $(T$. reesei transformant strains SB 6, SB 11 and SB 23) were isolated (Fig. 2). Confirmation that a gene disruption event had

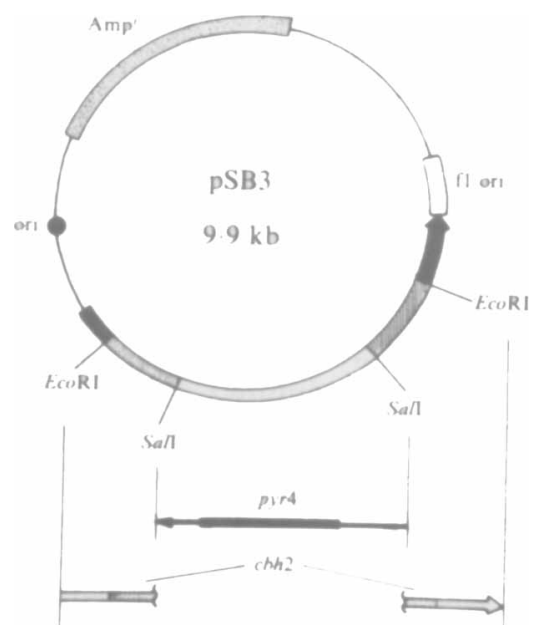

Fig. 1. Physical map of plasmid pSB3 used for interrupting the $c b h 2$ gene of $T$. reesei in this study. Open box, pyr 4 of $T$. reesei (the arrow below shows the $5^{\prime}$ orientation, and the coding regions drawn thicker than the rest); shaded region, $c b h 2$ from $T$. reesei (arrow shows $5^{\prime}$ orientation, with the coding region shaded). 


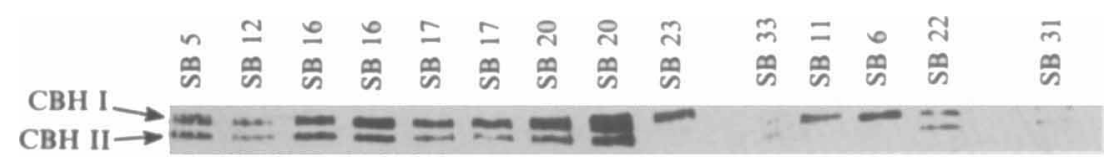

Fig. 2. Screening of $c b h 2$ gene disruption in strains of $T$. reesei grown on lactose as carbon source. Strains were grown for $4 \mathrm{~d}$, and then $20 \mu \mathrm{l}$ aliquots of the culture supernatant were subjected to SDS-PAGE and Western blotting. The blots were subsequently stained with monoclonal antibodies against CBH I and CBH II; positions of the bands are indicated by arrows. Individual stable transformants are indicated by their SB number over each track.

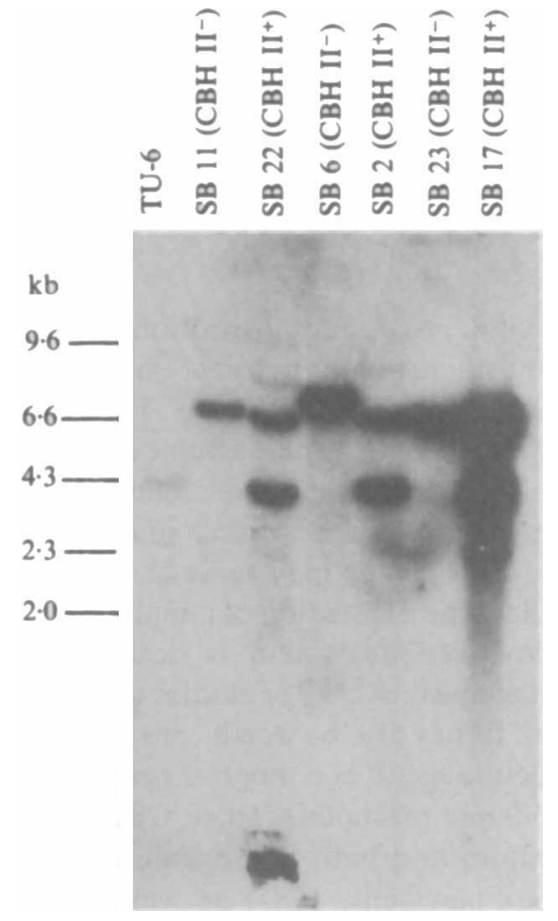

Fig. 3. Comparison by Southern blot analysis of T. reesei TU 6 (pyr4negative) and some of the transformants. Genomic DNA (1-2 $\mu \mathrm{g})$ was digested with EcoRI, fractionated by electrophoresis on a $0.8 \%$ gel, blotted to nylon membrane (Hybond-N; Amersham), and probed with a $2 \cdot 15 \mathrm{~kb}$ Sal $/ \mathrm{Bg} / \mathrm{I}$ fragment of the $T$. reesei cbh 2 gene. Molecular mass markers (in kb) are indicated on the left. Strains and their phenotypes (in parentheses) are indicated over each track. occurred was provided by Southern blotting of genomic DNA that had been digested with EcoRI. In $T$. reesei TU-6, $c b h 2$ was detected on a single $4.2 \mathrm{~kb}$ fragment. The predicted increase in size of the $E c o$ RI fragment of the cbh2 gene from 4.2 to $6.9 \mathrm{~kb}$ was observed in all transformants. However, in the strains that lacked the CBH II protein band in immunostaining of SDS-PAGE/ Western blots, the $6.9 \mathrm{~kb}$ fragment was the only one, indicating integration at the $c b h 2$ locus (Fig. 3).

\section{Induction of cellulase formation in the $\mathrm{CBH} \mathrm{II}^{-} \mathrm{T}$. reesei strain}

The final titre of CBH I, formed by all the various transformant strains of $T$. reesei during growth on lactose, was roughly the same (data not given), which suggested that their capacity fon cellulase secretion was not altered by transformation and the subsequent screening procedure. In order to confirm that their inducibility of cellulase formation was indeed comparable, three randomly chosen $\mathrm{CBH} \mathrm{II}^{+}$positive (SB 5, SB 17 and SB 20) and three CBH $\mathrm{II}^{-}$transformants, as well as the original strain QM 9414, were pre-grown on glycerol as carbon source, and then transferred to a replacement medium containing sophorose to induce cellulase formation. The results obtained were comparable within each group of transformants, and are shown for QM $9414\left(\mathrm{CBH} \mathrm{II}^{+}\right)$and SB $11\left(\mathrm{CBH} \mathrm{II}^{-}\right)$in Fig. 4:
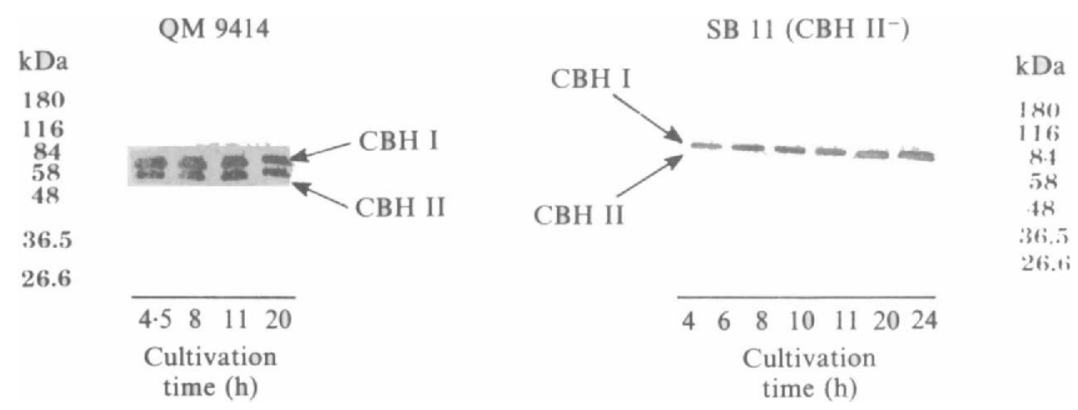

Fig. 4. Induction of CBH I and II formation by sophorose in $T$. reesei QM 9414 and in transformant SB-11. Strains were induced by $4 \mathrm{mM}$-sophorose, and samples of the culture supernatant were withdrawn after the times indicated and subjected to SDS-PAGE and Western blotting. Staining with monoclonal antibodies against CBH I and II was carried out. The relative positions of molecular mass marker proteins and the positions of CBH I and II are indicated. 

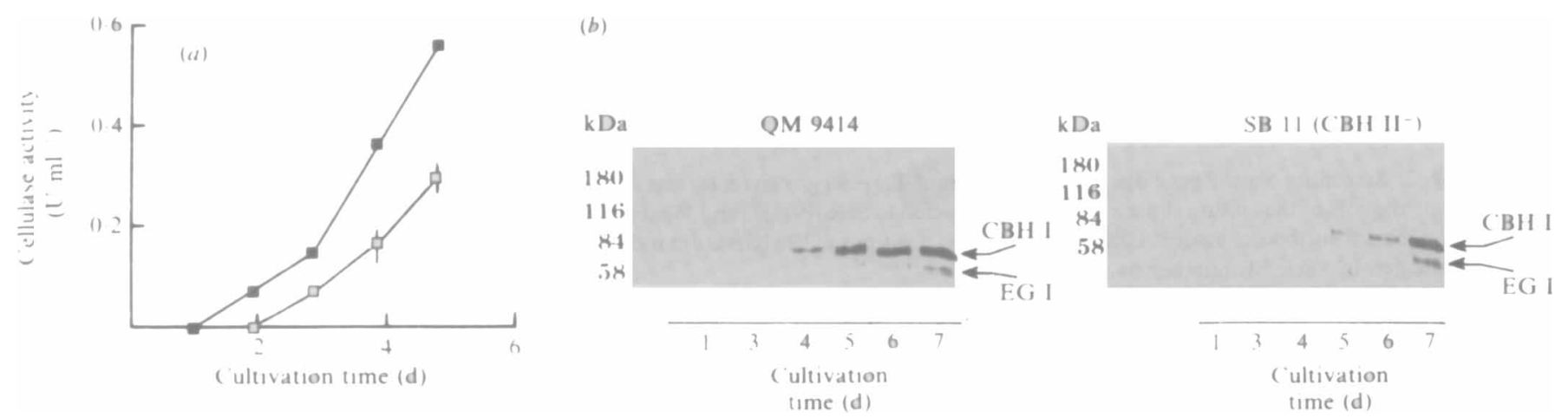

Fig. 5. Formation of cellulase activity (a) and CBH I and EG I (b) by T. reesei QM 9414 ( $\square$ ) and by transformant SB 11 ( $\square$ ) during growth on Avicel cellulose. Samples were withdrawn after the times indicated and the supernatant subjected to activity assay or to SDSPAGE/Western blotting. Immunostaining was carried out subsequently, using monoclonal antibodies CH-6 (Mischak et al., 1989) and EG-3 (Luderer et al., 1991) to detect CBH I and EG I, respectively. The relative positions of molecular mass marker proteins and of CBH I and EG I are indicated.

irrespective of the presence of an intact $c b h 2$ gene, both strains started to produce $\mathrm{CBH}$ I immediately after transfer to the sophorose-containing medium, showing maximal titres after about 20-24 h. Quantification by the dot-blot immunotechnique indicated roughly equal levels of secreted CBH I (73 and $68 \mu \mathrm{g} \mathrm{ml}^{-1}$, respectively).

\section{Growth and cellulase formation of $\mathrm{CBH} \mathrm{II}^{-}$strains on cellulose as a carbon source}

In our initial experiments, when $\mathrm{CBH} \mathrm{II}^{+}$and $\mathrm{CBH} \mathrm{II}^{-}$ transformants were grown on cellulose as carbon source, no specific differences in the rate of cellulase formation was observed between them (data not shown). Since the cellulase-production medium of $T$. reesei contains peptone, which is used as a carbon source prior to cellulose (unpublished results), we suspected that this may mask a possible difference between the strains. These experiments were therefore repeated with media from which peptone had been omitted. The results (shown for QM 9414 and SB 11, respectively; Fig. 5) indicated that the $\mathrm{CBH} \mathrm{II}^{-}$strain required about $18-24 \mathrm{~h}$ longer to induce cellulase formation on cellulose. Its growth was correspondingly delayed. Thereafter, however, the rate of enzyme formation was comparable to that of the $\mathrm{CBH}$ $\mathrm{II}^{+}$control. Quantification of the amount of CBH I secreted into the medium by dot-blot scanning (John et al., 1984) yielded consistent results.

The delayed growth of the $\mathrm{CBH} \mathrm{II}^{-}$transformants was specifically observed on cellulose as carbon source, and not on maltose, glycerol and lactose (data not shown).

\section{Discussion}

The present paper is the first to describe the construction and properties of a $\mathrm{CBH} \mathrm{II}^{-}$recombinant strain of $T$. reesei, although $c b h 2$-gene disruption has been also carried out by others (Suominen et al., unpublished data; cited in Uusitalo et al., 1991; A. Harkki, personal communication). Besides the usefulness of this phenotype in studies on the regulation of cellulase formation as described here - such strains may serve various attractive purposes: they may serve as recipient strains ir st'ndies where the expression of a manipulated copy of $c b h 2$ in a homologous system is desirable (e.g. sitedirected mutagenesis of $c b h 2$ or studies on the function of its promoter). It may also be worth considering the use of the $c b h 2$ structural gene as a reporter gene in the study of other Trichoderma promoters, since CBH II is secreted into the medium and both fluorogenic substrates (Van Tilbeurgh \& Claeyssens, 1985) as well as monoclonal antibodies (Mischak et al., 1989) are available for detection of CBH II with high sensitivity. This is particularly worthwhile, since conventionally used reporter genes (lacZ, uidA; cf. Van Gorcom \& Van den Hondel, 1988; Roberts et al., 1989) are not secreted and the gene products are prone to proteolysis.

An additional application of a $\mathrm{CBH} \mathrm{II}^{-}$strain is that it may serve as a source for purifying endoglucanase (EG) I that is essentially free of CBH II. Due to the very similar physico-chemical properties of EG I and CBH II (Enari \& Niku-Paavola, 1987; Kubicek, 1992), and the appearance of enzyme-enzyme complexes (Tomme et al., 1990), purification of either enzyme from culture filtrates of $T$. reesei is difficult, and cross-contaminated 'purified' preparations actually caused some confusion about the substrate specificities of these two enzymes, and their contribution to the synergistic breakdown of cellulose (Kyriacou et al., 1987). Penttilä et al. (1987) solved this problem by expressing individual cellulase cDNAs in Saccharomyces cerevisiae, to obtain single enzymes only. This strategy, however, suffers from the drawback that the cellulases secreted by yeast are overglycosylated 
(Penttilä et al., 1987; Van Arsdell et al., 1987), which may affect some enzymic properties. We thus recommend the use of a $\mathrm{CBH} \mathrm{II}^{-} T$. reesei strain for purifying EG I.

We used $\mathrm{CBH} \mathrm{II}^{-}$strains of $T$. reesei to elucidate the role of $\mathrm{CBH}$ II in triggering cellulase formation. The results showed that strains lacking $\mathrm{CBH}$ II exhibit a considerable lag in growth on cellulose and corresponding cellulase formation. This finding is in accordance with the postulation of a major role of CBH II in cellulase induction by cellulose (Messner et al., 1991), although it clearly shows that $\mathrm{CBH}$ II is not essential for this process. Apparently, in the absence of CBH II, CBH I also can initiate the attack on cellulose, albeit at a lower rate. On the other hand, similar growth and cellulase formation rates were observed with $\mathrm{CBH} \mathrm{II}^{-}$and $\mathrm{CBH} \mathrm{II}^{+}$strains when peptone was present in the cellulose-containing medium. In this case, the conidia germinate while using peptone as a carbon source and the mycelium starts to secrete cellulases into the medium which then attack cellulose. Since the hyphae secrete EG I, it is possible that the synergism between CBH I and EG I is sufficient for an optimal rate of hydrolysis, and thus CBH II is dispensable. Such an assumption also appears to be substantiated by the findings that growth of $\mathrm{CBH} \mathrm{II}^{-}$ strains on cellulose, after overcoming the lag, took place at a rate comparable to the $\mathrm{CBH} \mathrm{II}^{+}$strains. Thus the lag during the phase of initial attack by the conidial-bound cellulases is most probably the result of the fact that they lack EG I (Messner et al., 1991), and the CBH II- strains therefore contain only a single cellulase. The data are therefore consistent with the assumption that a synergism of at least two cellulolytic enzymes is needed for an optimal rate of cellulolysis (Henrissat et al., 1985).

If these interpretations are correct, then we are faced with the fact that $T$. reesei conidia use 'exo-exo'synergism, whereas $T$. reesei mycelia may use both 'exoendo' as well as 'exo-exo' synergism to degrade cellulose. It is tempting to speculate on the physiological advantages of these two different mechanisms.

\section{References}

BURNETTE, W. N. (1981). 'Western blotting': electrophoretic transfer of proteins from sodium dodecyl sulfate-polyacrylamide gels to unmodified nitrocellulose and radiographic detection with antibody and radioiodinated protein A. Analytical Biochemistry 112, 195-203.

El Gogary, S., leite, A., Crivellaro, O., Eveleigh, D. E. \& El DORRY, H. (1989). Mechanism by which cellulose triggers cellobiohydrolase I gene expression in Trichoderma reesei. Proceedings of the National Academy of Sciences of the United States of America 86, 6138-6142.

ENARI, T. M. \& NikU-PaAvola, M. L. (1987). Enzymatic hydrolysis of cellulose. CRC Critical Reviews in Biotechnology 5, 67-87.

Fritscher, C., Messner, R. \& Kubicek, C. P. (1990). Cellobiose metabolism and cellobiohydrolase I biosynthesis by Trichoderma reesei. Experimental Mycology 14, 405-415.
Gruber, F., Visser, J., Kubicek, C. P. \& De Graaff, L. (1990a). The development of a heterologous transformation system for the cellulolytic fungus Trichoderma reesei based on a pyrG-negative strain. Current Genetics 18, 71-76.

Gruber, F., Visser, J., Kubicex, C. P. \& De GraafF, L. (1990b). Cloning of the Trichoderma reesei pyrG gene and its use as a homologous marker for a high-frequency transformation system. Current Genetics 18, 447-451.

Henrissat, B., Driguez, H., Viet, C. \& Schülein, M. (1985). Synergism of cellulases from Trichoderma reesei in the degradation of cellulose. Bio/Technology 3, 722-726.

John, R., Schiebler, W. \& Greengard, P. (1984). A quantitative dotblot immunobinding assay for proteins using nitrocellulose membrane filters. Proceedings of the National Academy of Sciences of the United States of America 81, 1684-1687.

KUBICEK, C. P. (1982). $\beta$-Glucosidase excretion in Trichoderma pseudokoningii: correlation with cell wall bound $\beta$-1,3-glucanase activities. Archives of Microbiology 132, 349-354.

KUBICEK, C. P. (1987). Involvement of a conidial endoglucanase and a plasma membrane bound $\beta$-glucosidase in the induction of endoglucanase synthesis by cellulose in Trichoderma reesei. Journal of General Microbiology 133, 1481-1487.

KUBICEK, C. P. (1992). The cellulase proteins of Trichoderma reesei: structure, multiplicity, mode of action and regulation of formation. Advances in Biochemical Engineering and Biotechnology (in the Press).

Kubicex, C. P., Mühlbauer, G., Grotz, M., John, E. \& KubiceKPranz, E. M. (1988). Properties of a conidial-bound cellulase enzyme system from Trichoderma reesei. Journal of General Microbiology 134, 1215-1222.

Kubicek-Pranz, E. M., Gruber, F. \& Kubicek, C. P. (1991). Transformation of Trichoderma reesei with the cellobiohydrolase II gene as a means for obtaining strains with increased cellulase production and specific activity. Journal of Biotechnology 20, 83-94

K yriacou, A., MacKenzie, C. R. \& Neufeld, R. J. (1987). Detection and characterization of the specific and non-specific endoglucanases of Trichoderma reesei: evidence demonstrating endoglucanase activity by cellobiohydrolase II. Enzyme and Microbial Technology 9, 25-32.

LAEMMLI, U. K. (1970). Cleavage of structural proteins during the assembly of the head of bacteriophage T4. Nature, London 227, 680685.

Luderer, M. E. H., Hofer, F., Hagspiel, K., Allmaier, G., BlaAs, D. \& KUBICEK, C. P. (1991). A re-appraisal of multiplicity of endoglucanase I from Trichoderma reesei using monoclonal antibodies and plasma desorption mass spectrometry. Biochimica et Biophysica Acta 1076, 427-434.

Mandels, M. (1985). Cellulases. Annual Reports on Fermentation Processes 5, 35-78.

Messner, R., Kubicex-Pranz, E. M., Gsur, A. \& Kubicek, C. P. (1991). Cellobiohydrolase II is the main conidial-bound cellulase in Trichoderma reesei and other Trichoderma strains. Archives of Microbiology 155, 601-606.

Miller, B. L., Miller, K. Y. \& Timberlake, W. E. (1985). Direct and indirect gene replacements in Aspergillus nidulans. Molecular and Cellular Biology 5, 1714-1721.

Mischak, H., Hofer, F., Messner, R., Weissinger, E., Hayn, M., Tomme, P., Esterbauer, H., Küchler, E., Claeyssens, M. \& KUBICEK, C. P. (1989). Monoclonal antibodies against different domains of cellobiohydrolase I and II from Trichoderma reesei. Biochimica et Biophysica Acta 990, 1-7.

Penttilä, M. E., Andre, L., Saloheimo, M., Lehtovaara, P. \& KNOWLES, J. K. C. (1987). Expression of two Trichoderma reesei endoglucanases in the yeast Saccharomyces cerevisiae. Yeast 3, 175185.

Roberts, I. N., Oliver, R. P., Punt, P. J. \& Van den Hondel, C. A. M. J. J. (1989). Expression of the Escherichia coli $\beta$ glucuronidase gene in industrial and phytopathogenic filamentous fungi. Current Genetics 15, 177-180.

STERnBerG, G. \& MANDELS, G. R. (1979). Induction of cellulolytic enzymes in Trichoderma reesei by sophorose. Journal of Bacteriology 139, 761-767. 
Tomme, P., Heriban, V. \& Claeyssens, M. (1990). Adsorption of two cellobiohydrolases from Trichoderma reesei to avicel: evidence for "exo-exo" synergism and possible "loose complex" formation. Biotechnology Letters 12, 525-530.

UMILE, C. \& KUBICEK, C. P. (1986). A constitutive, plasma-membrane bound $\beta$-glucosidase in Trichoderma reesei. FEMS Microbiology Letters 34, 291-295.

Uusitalo, J. M., Nevalainen, K. M. H., Harkki, A. M., Knowles, J. K. C. \& PentTILÄ, M. E. (1991). Enzyme production by recombinant Trichoderma reesei strains. Journal of Biotechnology 17, 35-50.
Van Arsdell, J. N., KwoK, S., Schweikart, V. L., Ladner, M. B. GeLfaND, D. H. \& INNIS, M. A. (1987). Cloning, characterization and expression in Saccharomyces cerevisiae of endoglucanase I from Trichoderma reesei. Bio/Technology 5, 60-64.

VAN GoRCOM, R. F. M. \& VAN DEN HONDEL, C. A. M. J. J. (1988). Expression analysis vectors for Aspergillus niger. Nucleic Acids Research 16, 9052.

Van TilbeurGh, H. \& Clakyssens, M. (1985). Detection and differentiation of cellulase components using low molecular mass fluorogenic substrates. FEBS Letters 187, 283-288. 